\title{
Nanocrystalline M-Type Hexaferrite Powders: Preparation, Geometric and Magnetic Properties
}

\author{
P. Görnert, H. Pfeiffer, E. Sinn, R. Müller and W. Schüppel \\ Institut für Physikalische Hochtechnologie, Helmholtzweg 4, Postfach 100239, D-07702 Jena, Germany \\ M. Rösler \\ Forschungsinstitut für Pigmente und Lacke, Allmandring 37, D-70569 Stuttgart, Germany \\ X. Batlle, M. Garcia del Muro, J. Tejada and S. Gali \\ Universitat de Barcelona, Diagonal 647, 08028 Barcelona, Catalonia, Spain
}

\begin{abstract}
Co-Ti-Sn-Ge substituted M-type bariumhexaferrite powders with mean grain sizes between about $10 \mathrm{~nm}$ and about $1 \mu \mathrm{m}$ and a narrow size distribution were prepared reproducibly by means of a modified glass crystallization method. At annealing temperatures between 560 and $580{ }^{\circ} \mathrm{C}$ of the amorphous flakes nanocrystalline particles grow. They behave superparamagnetically at room temperature and change into stable magnetic single domains at lower temperatures. The magnetic volume of the powders is considerably less than the geometric one. However, the effective anisotropy fields are larger by a factor of two to three.
\end{abstract}

\section{INTRODUCTION}

The application of micro- and submicrocrystalline M-type hexaferrite powders for permanent magnets and magnetic recording is well known. Such powders consist of individual single crystalline and single domain hexaferrite particles with diameters of about $40-400 \mathrm{~nm}$, which can be produced in different way [1]. We believe that the glass crystallization method [1-6] gives the best particle ensembles [7-10]. In this paper we report on the reproducible preparation and the characterization of nanocrystalline Co-Ti-Sn-Ge substituted M-type bariumhexaferrite powders with sizes of a few lattice cells (diameter $\approx 10 \mathrm{~nm}$ ) and a narrow size distribution. The powders have been prepared by means of a modified glass crystallization method. Our nanocrystalline hexaferrite particles behave superparamagnetically at room temperature; they change into stable magnetic single domains at lower temperatures - below the blocking temperature. Obviously, the smallest particles are already paramagnetic. Nanocrystalline hexaferrite powders can be applied e.g. [11] for new ferrofluids - the common ferrofluids consist of $\mathrm{Fe}$ or $\mathrm{Fe}_{3} \mathrm{O}_{4}$ suspensions.

Section II of this paper describes the preparation and the geometric properties of nanocrystalline hexaferrite powders. Structural characterization has been carried out by means of

Manuscript received May 31, 1993
X-ray diffraction, TEM, HRTEM, and BET. Section III is focused to some magnetic properties.

\section{PREPARATION AND GEOMETRIC PROPERTIES OF NANOCRYSTALLINE HEXAFERRITE POWDERS}

By means of glass crystallization [1-10] we prepared $\mathrm{BaFe}_{12}$ ${ }_{2 x} \mathrm{Co}_{\mathrm{x}} \mathrm{Ti}_{\mathrm{x}-\mathrm{y}-\mathrm{z}} \mathrm{Sn}_{\mathrm{y}} \mathrm{Ge}_{\mathrm{z}} \mathrm{O}_{19}$ powders with $\mathrm{x}=0.8, \mathrm{y}=\mathrm{z}=0$ (Co-Ti);
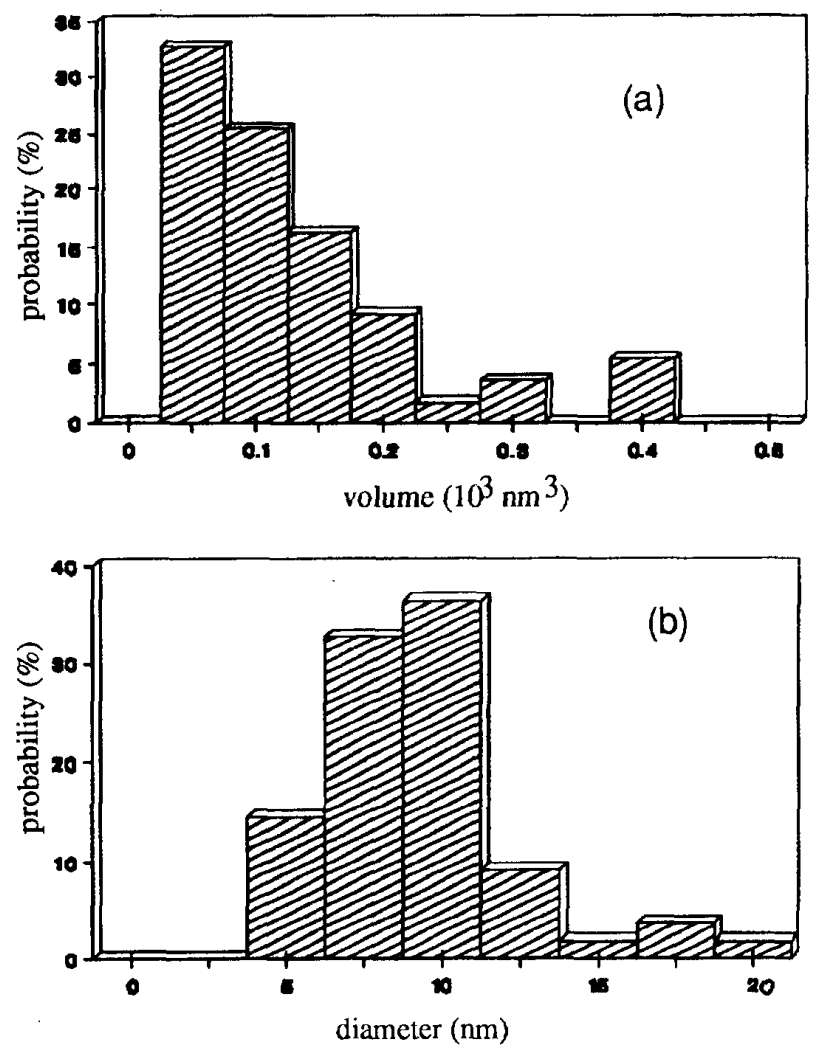

Fig.1. Volume (a) and diameter (b) distribution of the Co-Ti-Sn-Ge powder revealed by TEM 
TABLE I

GEOMETRIC AND MAGNETIC PROPERTIES OF Co-Ti, Ca-Ti-Sn AND Co-Ti-Sn-Ge POWDERS

\begin{tabular}{|c|c|c|c|}
\hline geometric properties & Co-Ti & Co-Ti-Sn & Co-Ti-Sn-Ge \\
\hline $\begin{array}{l}\text { TEM mean diameter }(\mathrm{nm}) \\
\text { TEM mean thickness }(\mathrm{nm}) \\
\text { BET specific surface }\left(\mathrm{m}^{2} / \mathrm{g}\right) \\
\text { TEM specific surface }\left(\mathrm{m}^{2} / \mathrm{g}\right)\end{array}$ & $\begin{array}{c}10.2 \\
112 \\
-\end{array}$ & $\begin{array}{c}24.4 \\
5.3 \\
116 \\
88\end{array}$ & $\begin{array}{c}8.1 \\
- \\
124\end{array}$ \\
\hline \multicolumn{4}{|l|}{ magnetic properties at RT } \\
\hline $\begin{array}{l}\text { specific magnetization at } \mathrm{H} \rightarrow \infty\left(\mathrm{Gcm}^{3} / \mathrm{g}\right) \\
\text { coercivity }(\mathrm{Oe}) \\
\text { remanence ratio } \mathrm{M}_{\mathrm{r}} / \mathrm{M}_{\mathrm{s} \infty} \\
\text { Curie temperature }(O \mathrm{C})\end{array}$ & $\begin{array}{l}17.3 \\
8.5 \\
0.003(?) \\
360\end{array}$ & $\begin{array}{l}21.4 \\
68 \\
0.07 \\
348\end{array}$ & $\begin{array}{c}15.0 \\
15 \\
0.006(?) \\
342\end{array}$ \\
\hline
\end{tabular}

$x=0.85, y=0.4, z=0$ (Co-Ti-Sn) and $x=0.8, y=0.25, z=0.10$ (Co-Ti-Sn-Ge) characterized in Table 1.

In order to get very small particles by glass crystallization we checked three possibilities: (i) suitable chemical glass compositions, which favour nucleation of barium borate and hexaferrite during annealing of the amorphous flakes [1] (ii) short enough annealing times, and/or (iii) as low as possible annealing temperatures.

Our experiments revealed that very short annealing times of flakes are not convenient in our system because nucleation and crystal growth by diffusion proceeds at higher temperatures $\left(\geq 700^{\circ} \mathrm{C}\right)$ in less than $100 \mathrm{~s}$ and at lower temperatures iron oxide compounds are formed. Time intervals in the order of $100 \mathrm{~s}$ are too small for the formation of a homogeneous temperature distribution within the flakes. Nanocrystalline particles grow during annealing for longer times at temperatures of $560-580{ }^{\circ} \mathrm{C}$ depending on the chemical composition of the flakes. A reduction of the mean particle size by roughly a factor of four is achieved e.g. by Co-Ti substitutions $[5,1]$.

Concerning the unsubstituted ferrites $\mathrm{BaFe}_{12} \mathrm{O}_{19}$ we improved the nucleation in the flakes by addition of small amounts $(\approx 1 \mathrm{~mol} \%)$ of suitable compounds. These additions as well as the substitutions mentioned above decrease the temperature necessary for the formation of the hexaferrite phase. It is not sure whether or not such additions are incorporated into the hexaferrite particles.

Fig. 1 as well as Table 1 clearly show that the mean particle diameter reaches a value of about $8 \mathrm{~nm}$. Electron diffraction and HRTEM studies on selected platelets prove the existence of the M-type structure in agreement with former results on microcrystalline particles [8]. The electron diffraction reflexes are slightly broadened because of the low particle sizes. Very small particles possess a spherical shape. The X-ray diffraction measurements disclose very broad peaks. Some reflexes disappear completely.

The specific surfaces of typical substituted nanocrystalline powders are in the range of $100-150 \mathrm{~m}^{2} / \mathrm{g}$ (see e.g. Table 1).

\section{III.MAGNETIC PROPERTIES}

We measured magnetic properties in dependence on temperature $(2-300 \mathrm{~K})$ as well as field $(\leq 50 \mathrm{kOe})$ and interpreted the experimental results in terms of theoretical models which were developed earlier. The ZFC (zero field cooled) and FC (field cooled) magnetization curves display the typical features of a small particle system [12] as shown in Fig. 2. The maximum of the ZFC magnetization at $T=T_{M}$ marks the transition from stable (Stoner-Wohlfarth) particles to superparamagnetic ones. $T_{M}=c<T_{B}>$ is proportional to the mean blocking temperature $\left\langle T_{B}\right\rangle$, where $1 \leq \mathrm{c} \leq 2$ depends on the width of particle distribution [13].

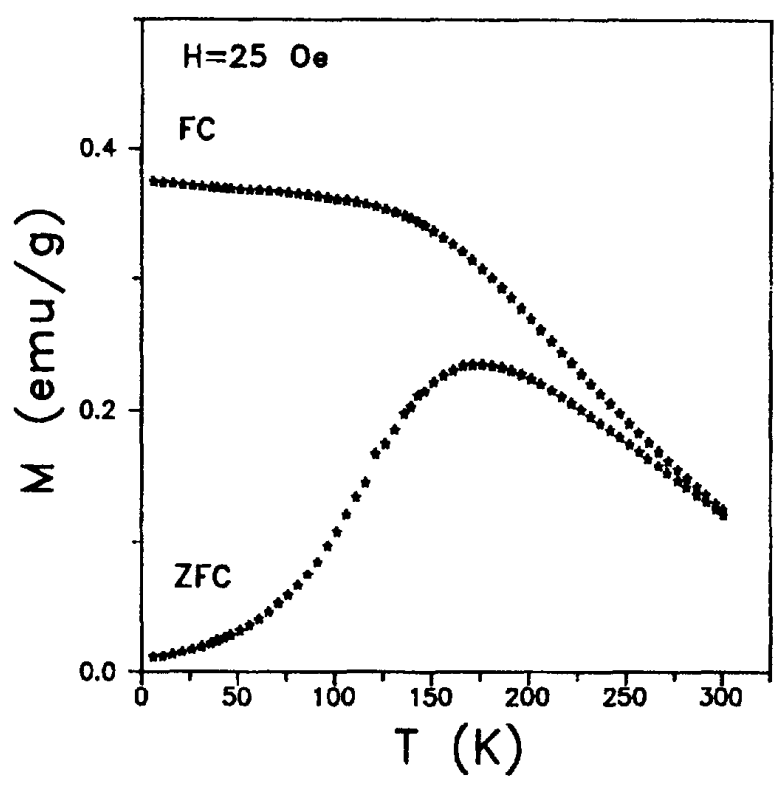

Fig. 2. Magnetization $M$ as a function of the temperature $T$ for the Co-Ti$\mathrm{Sn}$-Ge powder of Fig. 1 measured under zero field cooled (ZFC) and field cooled (FC) conditions 


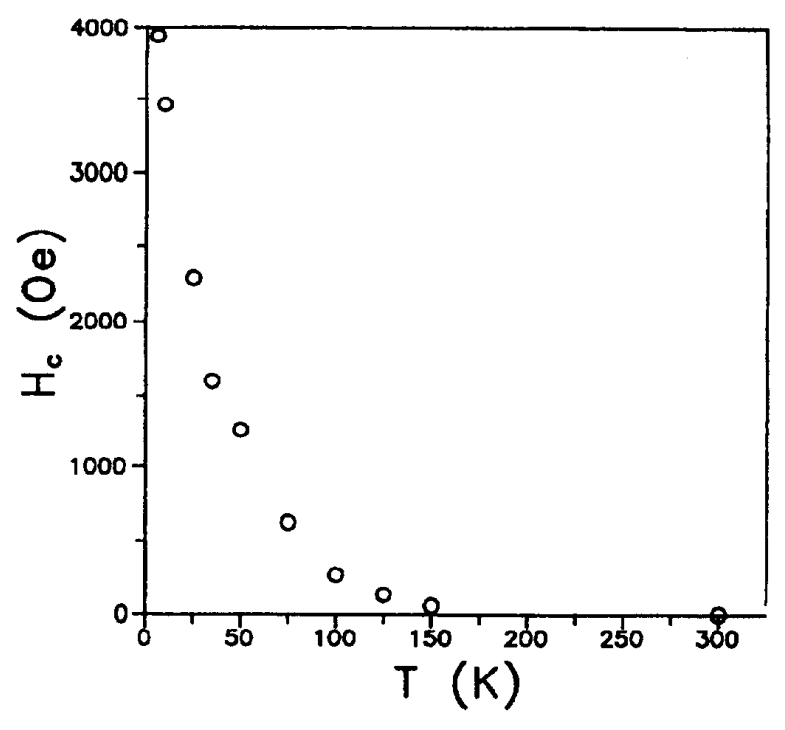

Fig.3. The coercivity $\mathrm{H}_{c}$ of the Co-Ti powder in dependence on the temperature $\mathrm{T}$

The transition "stable" $\rightarrow$ "superparamagnetic" is presented as well in the temperature dependence of the coercivity given in Fig. 3.

The occurrence of superparamagnetism at room temperature illustrated by the coercivities and the remanence ratios given in Table 1 can be understood easily by the well known relation for the time dependence of the remanent magnetization

$$
M_{R}(t)=M_{R}(0) \exp (-t / \tau)
$$

with the reciprocal relaxation time

$$
\tau^{-1}=f_{0} \exp \left(-K_{\mathrm{eff}} V / k_{B} T\right) .
$$

For $\mathrm{BaFe}_{12} \mathrm{O}_{19}$ at room temperature the effective anisotropy constant $K_{\text {eff }} \approx 3 \times 10^{5} \mathrm{~J} / \mathrm{m}^{3}$ and the frequency $f_{0} \approx 8 \times 10^{9} \mathrm{~s}^{-1}$ are valid; $k_{B}$ is Boltzmann's constant. As usual we set $\tau=$ $100 \mathrm{~s}$ and get the critical volume $V=V_{c} \approx 380 \mathrm{~nm}^{3}$ for superparamagnetism. Our actual volumes presented in Fig.1a are smaller. In fact, the $K_{\text {eff }}$ values of the Co-Ti substituted barium hexaferrites are even less by roughly a factor of three however, the $K_{\text {eff }}$ values of nanocrystalline particles are larger by a factor of two to three [15]. The effective anisotropy field of the Co-Ti substituted nanocrystalline powder characterized in Fig. 3 amounts $16 \mathrm{kOe}$ at a temperature $T \rightarrow 0 \mathrm{~K}$.

The magnetic volume and therefore the magnetization of all powders (cf. Table 1) is considerably less than the geometric one caused by effective "dead layers" parallel to the crystallographic c-surfaces of the particles with thicknesses $\delta$
$=1,3 \mathrm{~nm}$ for $\mathrm{BaFe}_{12} \mathrm{O}_{19}$ and $\delta=0.7 \mathrm{~nm}$ for $\mathrm{BaFe}_{10.2} \mathrm{Co}_{0.9} \mathrm{Ti}_{0.9} \mathrm{O}_{19}$ [8]. These data are in good agreement with a value of Kurisu et al. [14], who found $\delta=0.8 \mathrm{~nm}$ for $\mathrm{BaFe}_{10.26} \mathrm{Co}_{0.87} \mathrm{Ti}_{0.87} \mathrm{O}_{19}$. Obviously, the smallest particles are even paramagnetic.

\section{CONCLUSIONS}

- Nanocrystalline Co-Ti-Sn-Ge substituted M-type bariumhexaferrite powders with sizes of a few lattice cells (diameter $\approx 10 \mathrm{~nm}$ ) and a narrow size distribution can be reproducibly prepared by means of a modified glass crystallization method.

- The magnetic volume of the powders is considerably less than the geometric one caused by effective "dead layers" parallel to the crystallographic c- surfaces of the particles. The smallest particles are even paramagnetic.

- The Co-Ti substituted nanocrystalline powders exhibit unexpected large effective anisotropy fields of about $16 \mathrm{kOe}$ (at $T \rightarrow 0 \mathrm{~K}$ ) measured with different methods. This anisotropy field is larger by a factor of two to three compared with microcrystalline ones.

\section{REFERENCES}

[1] P.Gömen, E. Sinn and M. Rösler, "Preparation and characterization of hexaferrite powders," Key Eng. Mater., vol. 58 (1991) 129.

[2] B.T. Shirk and W.R. Buessem, "Magnetic properties of barium ferrite formed by crystallization of a glass," J. Am. Ceram. Soc., vol. 53 (1970) 192.

[3] O. Kubo, T. Ido, T. Nobura, K. Inomata, H. Yokoyama, DE 3041960 (1980/81).

[4] Toshiba Review No. 154 Winter (1985) 5.

[5] P. Gömert, E. Sinn, W. Schüppel, H. Pfeiffer, M. Rösler, Th. Schubert $M$. Jurisch and $R$. Sellger, "Structural and magnetic properties of $\mathrm{BaFe}_{12-2 x} \mathrm{Co}_{x} \mathrm{Ti}_{\mathrm{x}} \mathrm{O}_{19}$ powders prepared by the glass crystallization method," IEEE Trans. Magn., vol. 26 (1990) 12.

[6] P. Görnert, E. Sinn, H. Pfeiffer, W. Schüppel, and M. Rösler, "Glass crystallized barium ferrite powders for magnetic recording media," $J$. Magn. Soc. Japan, vol. 15, Suppl. No. S2 (1991) 669.

[7] P. Gömert, "Kinetics and mechanisms of flux crystal growth," Prug. Crystal Growth Charact., vol. 20 (1990) 263.

[8] M. Rösler, P. Görnent and E. Sinn, "Structural and magnetic properties of Ba-ferrite fine particles grown by glass crystallization," Z. Phys. $D$, vol. 19 (1991) 279.

[9] P. Gömert, E. Sinn and M. Rösler, "Barium ferrites for magnetic recording media," Mater. Sci. Forum, vol. 62-64 (1990) 573.

[10] P. Gömert, W. Schüppel, E. Sinn, F. Schumacher, K. A. Hempel, G. Turilli, A. Paoluzi, and M. Rösler, "Comparitive measurements of the

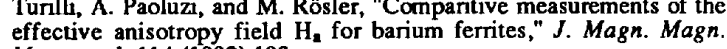
Mater., vol. 114 (1992) 193.

[11] K. Haneda, "Recent advances in the magnetism of fine particles," Can.J.Phys., vol. 65 (1987) 1233.

[12] X. Batlle, M. Garcia del Muro, J. Tejada, H. Pfeiffer, P. Görnert, and E. Sinn, "Magnetic study of M-type doped barium ferrite nanocrystalline powders," accepted in J. Appl. Phys.

[13] H. Pfeiffer and R. W. Chantrell, "Zero-field-cooled magnetization and initial susceptibility of magnetic particle systems," J. Magn. Magn. Mater., vol. 120 (1993) 203.

[14] S. Kurisu, T. Ido, H. Yokoyama, "Surface effect on saturation magnetization of $\mathrm{Co}$ and $\mathrm{Ti}$ substituted Ba-ferrite fine particles," IEEE Trans. Magn., vol. 23 (1987) 3137.

[15] H. Pfeiffer, W. Schüppel, P. Gömen, E. Sinn, R. Müller, X. Batlle, M. Garcia del Muro, and J. Tejada, "Magnetic properties of nanocrystalline barium hexaferrite powders: anisotropy field and interaction effects," J. Magn. Magn. Mater., in press. 